\title{
Implementation of Intelligent Control Technique for Fly Back Converter Based Photovoltaic System
}

\author{
Sivagami. $\mathrm{P}^{1}$, Sangramjith Mukherjee ${ }^{2}$, Suraj Chakraborty ${ }^{3}$, \\ M.Pushpavalli ${ }^{4}$, P . Abirami ${ }^{5}$ \\ $1,4,5$ Assistant Professor, ${ }^{2,3}$ UG Scholar \\ Department of Electical and Electronics Engineering. \\ Sathyabama Institute of Science and Technology,Chennai-119, \\ 1 sivagamitec@gmail.com, \\ ${ }^{4}$ pushpa.murugan@gmail.com, ${ }^{5}$ abiramiramkumar80@gmail.com
}

\begin{abstract}
In this technological era the need for power increases rapidly and in order to meet the demand of power requirement of the population, voltage harnessed from various renewable energy sources has to be controlled. In order to increase and maintain stable output voltage many strategies are evolved with the help of many theories and approaches. But on increasing voltage, it leads to fluctuation and ripples at the output during the operation thereby increasing the cost of every equipment as well as maintenance. One of the non-conventional free sources available in abundant SOLAR is gaining popularity not only because of nondepleting nature but it is pollution free, clean green energy source. It helps in harnessing maximum energy by converting the light available into useful energy. For Photo voltaic (PV), the converter proposed is a modification of the existing boost converter with Fly back converter. It is like boost converter but has an additional advantage of isolation. The proffered model implemented with the intelligent control MPPT technique, in which the response time taken by the controller is faster. The controller helps in harnessing the maximum energy though influenced by the environmental factors. It uses a two-stage H-bridge inverter which is an open-loop circuit that converts the DC output of the converter into AC. Thus, the voltage harnessed from the model has waveform which is sinusoidal in nature with minimized harmonics which are obtained by using LC filters and are finally fed to the load. The approaches using boost converter has made satisfactory results in the past few decades but with recent theories, fly back converter can now be proved as a better way This approach thereby leads to a cost-effective technique of voltage boosting for high voltage applications. Experimental result obtained using hardware setup validates the proffered model.
\end{abstract}

Keywords: Photo Voltaic array-PV, Sliding Mode Controller- SMC, Fuzzy logic controllerFLC, Fly back converter

\section{Introduction}

Homes and industries depend on energy sources for power which are depleting. Because of the limited resources today, power contribution to the world is by renewable as well as conventional energy sources. These sources join hands together to yield maximum energy to meet the demand requirement. But in few years the people in the world has to rely on only renewable energy sources. To overcome the future energy crisis, it becomes necessary to improve the efficiency of converters and controllers to harness maximum energy from renewable energy sources. Fly back converters helps in improving the energy conversion efficiency with an isolation structure between the source and the load. 
Modified conventional fly back converter topology improves the power efficiency by reducing the voltage and current components [1]. A sensor less approach using maximum power point tracking mode and constant power generation mode is proposed. MPPT mode helps in determining the available PV power. Usually PV power is determined by measuring insolation and temperature using sensors [2]. A modified Perturbation and observation algorithm based on 3point weight comparison to track maximum power [3]. Under dynamic environmental conditions the performance of $\mathrm{P} \& \mathrm{O}$ and IC is discussed. It is found that variations in insolation level affects the performance of IC and its efficiency decreases and is found to be less than 95\%. Adaptive MPPT technique proposed to yield high [4].

Fuzzy logic controller technique for stand-alone PV system yields high efficiency [5]. One of the approaches to gain maximum power from PV is by driving MPPT technique, using genetic algorithm [6]. The intelligent control technique Fuzzy logic control harness maximum power from the converter is proposed for grid connected [7]. Advanced MPPT technique using fuzzy logic controller regulates the PV output voltage better when compared to other methods available [8].

The coupled-inductor boost integrated fly back converter with high-voltage gain and ripple-free input current is proposed. Conventional fly back converter is modified to have a coupled inductor to reduce the input ripple current and to increase the voltage gain. A boostfly back converter is designed to enhance the power conversion efficiency. It is designed with a parallel PFC concept to have high efficiency and is small in size. The current component used for power point tracking replaced the use of sensors.

Dual-stage inverter topology operates with MPPT technique and also reduces ripples of the current at the input and output of the converter. Modified current control algorithm was proposed to track the maximum power. $\mathrm{H}$ bridge inverter fed by modified switched inductor boost converter with a shaping circuit for current to extract maximum power of PV. The performance of intelligent controller was compared with that of PID for Super lift LUO converter. The performance was better with that of the intelligent controller technique. Intelligent control technique implemented for tracking maximum power for $\mathrm{KY}$ boost converter.

\section{Modules of Proposed System}

The fly back converters are similar to the booster converters in architecture and performance. It consists of inductor similar to the transformer primary while the secondary providing the output is another inductor equivalent to that of secondary winding in a transformer. Thus, the power supply topology that includes mutually coupled inductor is the fly back converter, which stores energy when current passes through and release the energy when the power is removed. The fly back converter structure with inductor split is substitute to a transformer with the voltage ratios multiplied with an additional advantage of isolation. The factors influencing the power such as voltage and current from the PV panel acts as input source to fly back converter as well as fed to the fuzzy logic controller. The fuzzy logic MPPT controller compares the voltage and current from the previous measured values and generates a response quickly to act on the switches of the converter in order to maintain maximum power 
by controlling the on, off condition of the switches value. The boosted voltage by fly back converter acts as source for the inverter. The inverter has filter circuit to provide harmonic less sinusoidal output as input to the load. The module proposed is represented in figure 1.

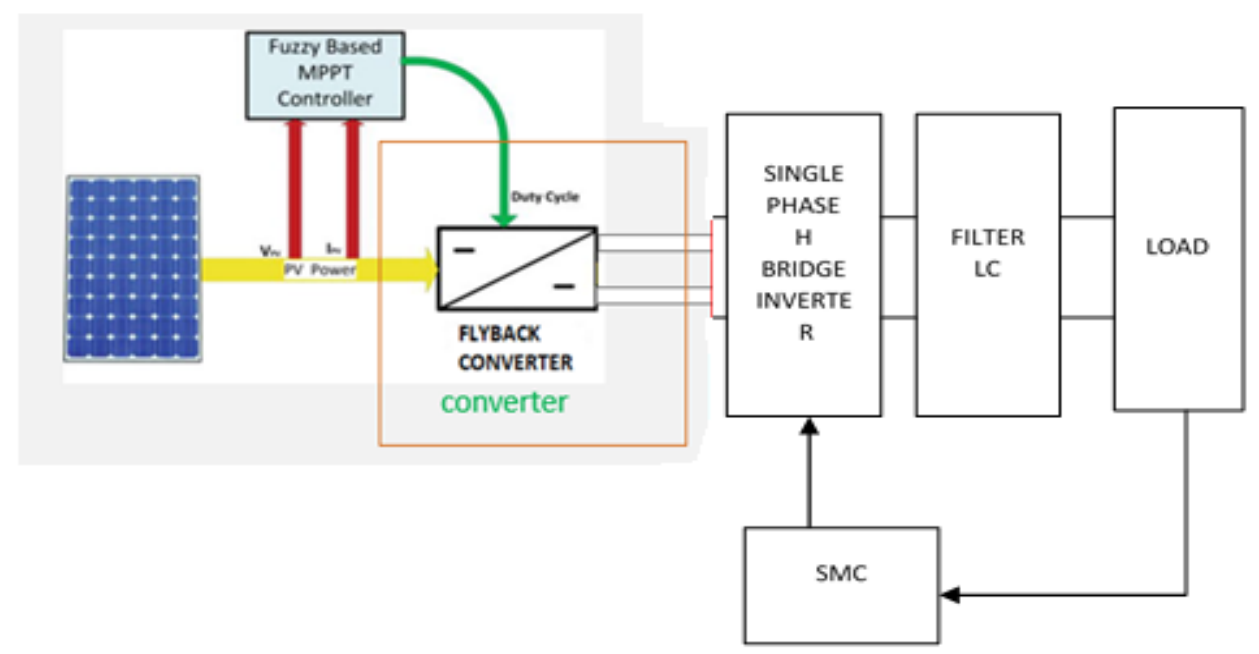

Fig. 1. Representation of module proposed

\section{Modes of Operation of Fly Back Converter System}

In mode 1 process the voltage in PV is applied to one of the split inductors equivalent to primary. The switch position during this operation is closed that is when PV voltage energizes the winding. During the switch in open position it is said to operate in mode 2 where it discharges the stored energy in the inductor to another inductor through mutual coupling action. It is delineated in figure 2 and figure 3.

\section{Controller Technique for Fly back converter System}

Controller helps in regulating the output of the plant by following its input to yield required result. There are many controllers available for regulating the output of the PV system. They are voltage mode controller, current mode controller, Proportional integral controller (PI), Proportional integral derivative controller (PID), intelligent controller etc. PID controller is based on frequency response and fuzzy controller is based on heuristic knowledge. The performance of controllers that is PID and fuzzy logic controller for fly back converter are discussed in this paper. 
Mostly in industrial applications a simplified controller such as Proportional integral controller (PI) or intelligent controller is opted instead of PID. This is because it has high sensitivity to interference. More over PID controller requires exact mathematical model and inference about uncertain inputs. The figure 4 shows the simulation diagram for PID controller employed in fly back converter. The figure 5 shows the output of PID controller for irradiance of 800 and temperature about $28{ }^{\circ} \mathrm{C}$. The output has ripples.

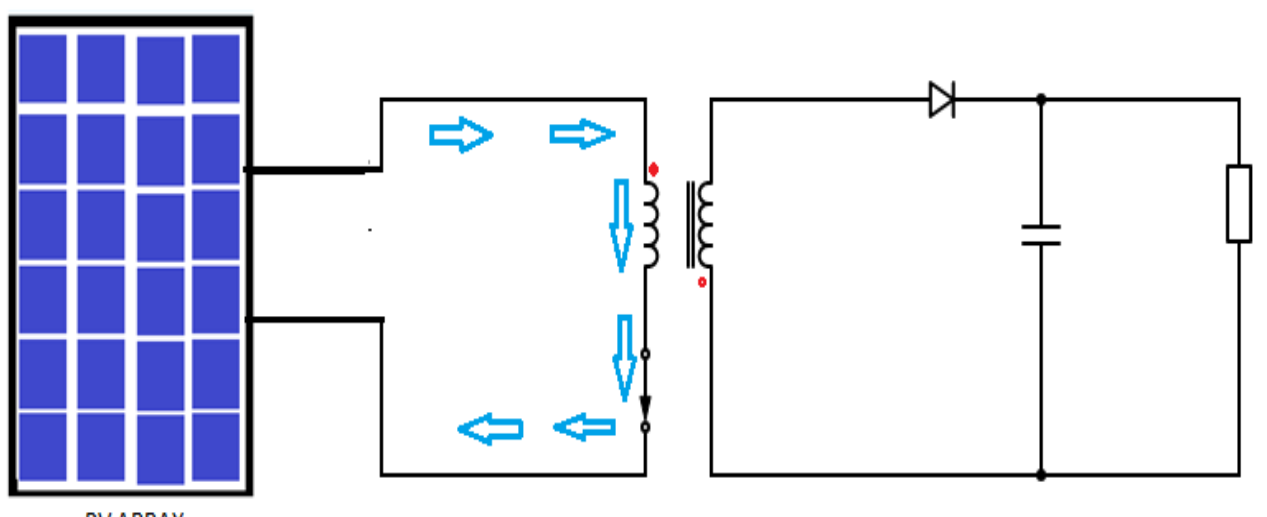

PV ARRAY

Fig. 2. Switch in closed position as charging circuit

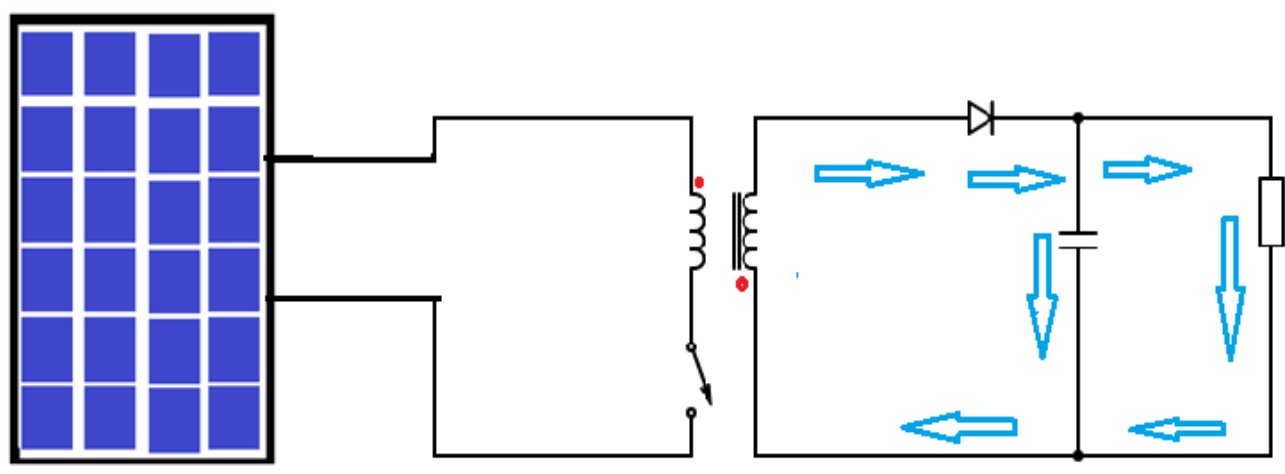

PV ARRAY

Fig. 3. Switch in open position as discharging circuit 


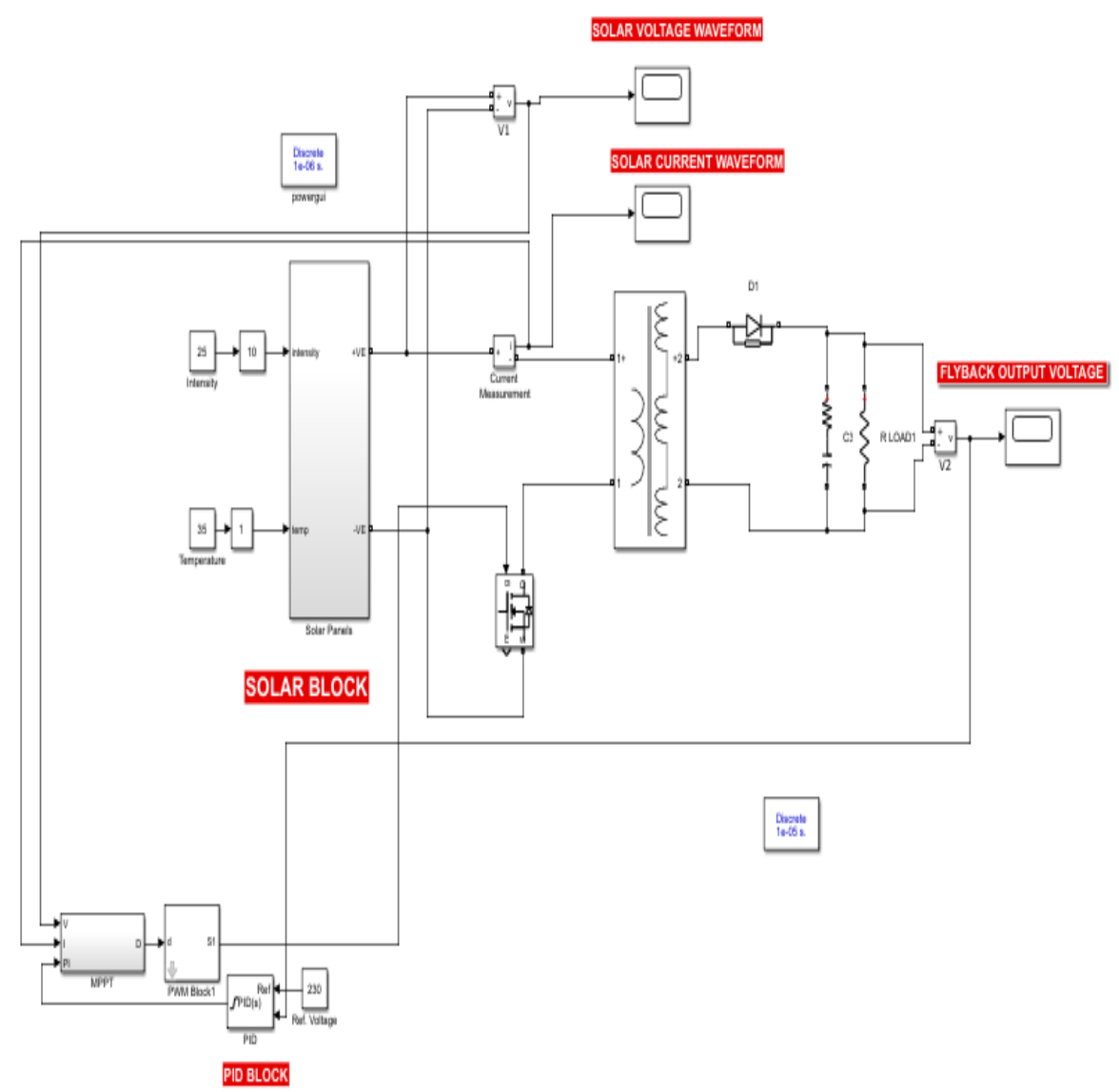

Fig. 4. Simulink model for PID controlled fly back converter

Fuzzy logic control helps in improving the controller systems by adding an intelligence to the controller. Fuzzification mutate crisp set to fuzzy set. It practices membership functions. The input to fuzzy set incorporates two parameter which are error, change in error. AND operator is performed between input sets. Linguistic labels are imputed in order to elucidate fuzzy sets. They are positive big, positive small, zero, negative big, negative small. The basic building ingot for molding rules are human experience and fundamental knowledge. In this proffered case the number of fuzzy sets available to control input is five. As a result, the number of outcomes that can be framed as rule is 25 . Duty cycle is the result obtained from a logical decision based on fuzzy rules framed by fuzzy inference system. The simulation diagram using fuzzy logic controller is depicted in figure 6 . The output with reduced ripples is shown in figure 7. The membership functions for error, change in 
error, output is delineated in figures 8,9 and 10 . The surface view and rule view are shown in figure11 and 12.

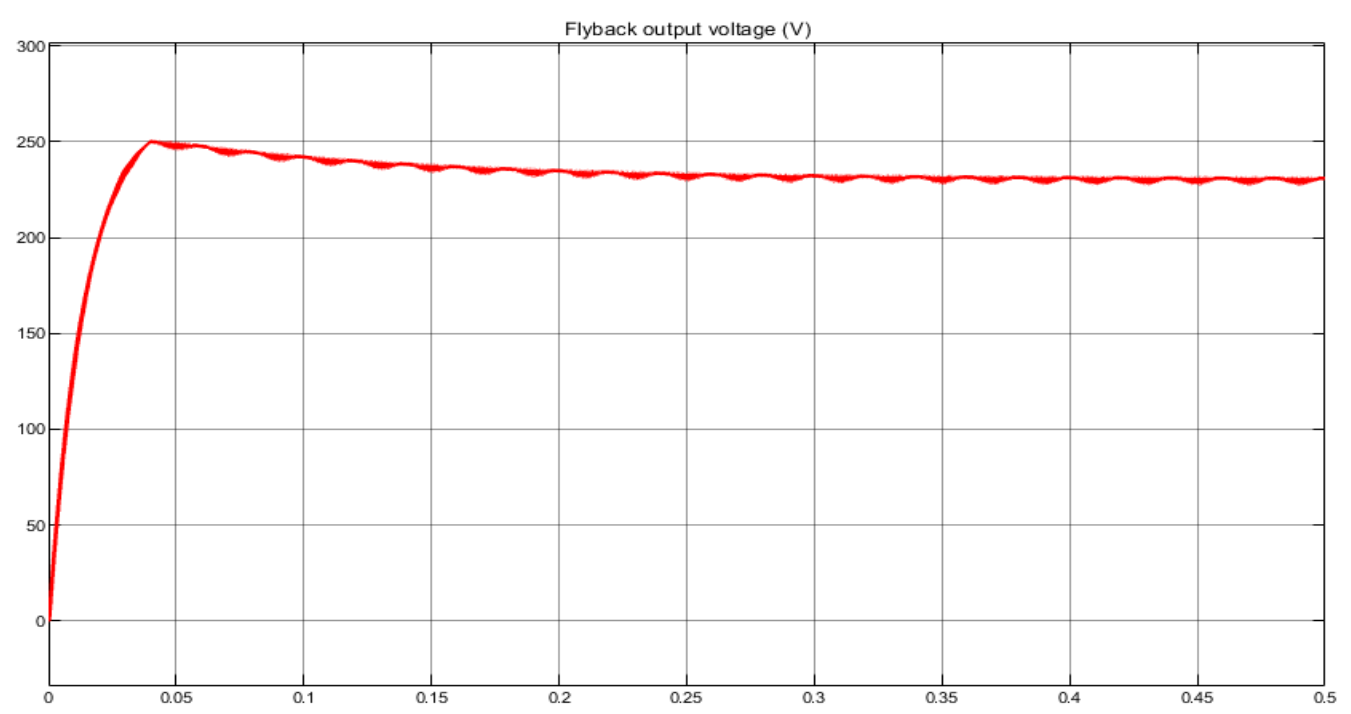

Fig.5. Output voltage for PID controlled fly back converter

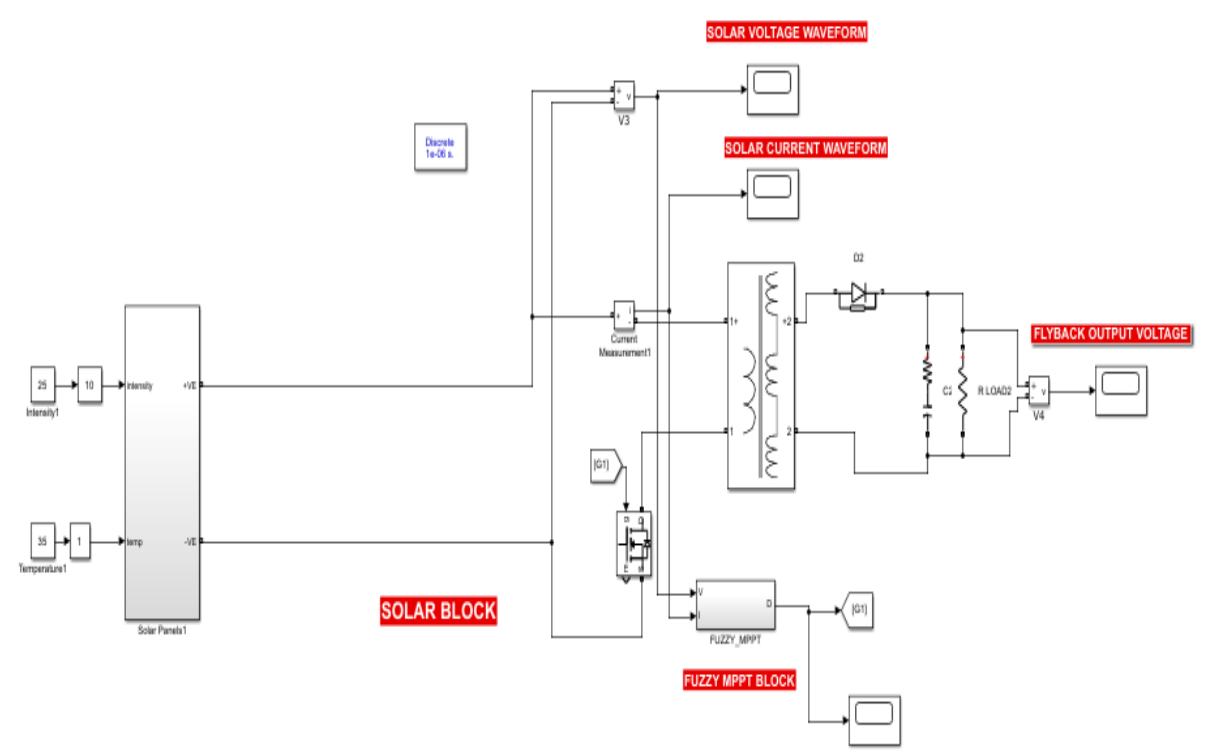

Fig.6.Simulink model for Fuzzy controlled fly back converter 


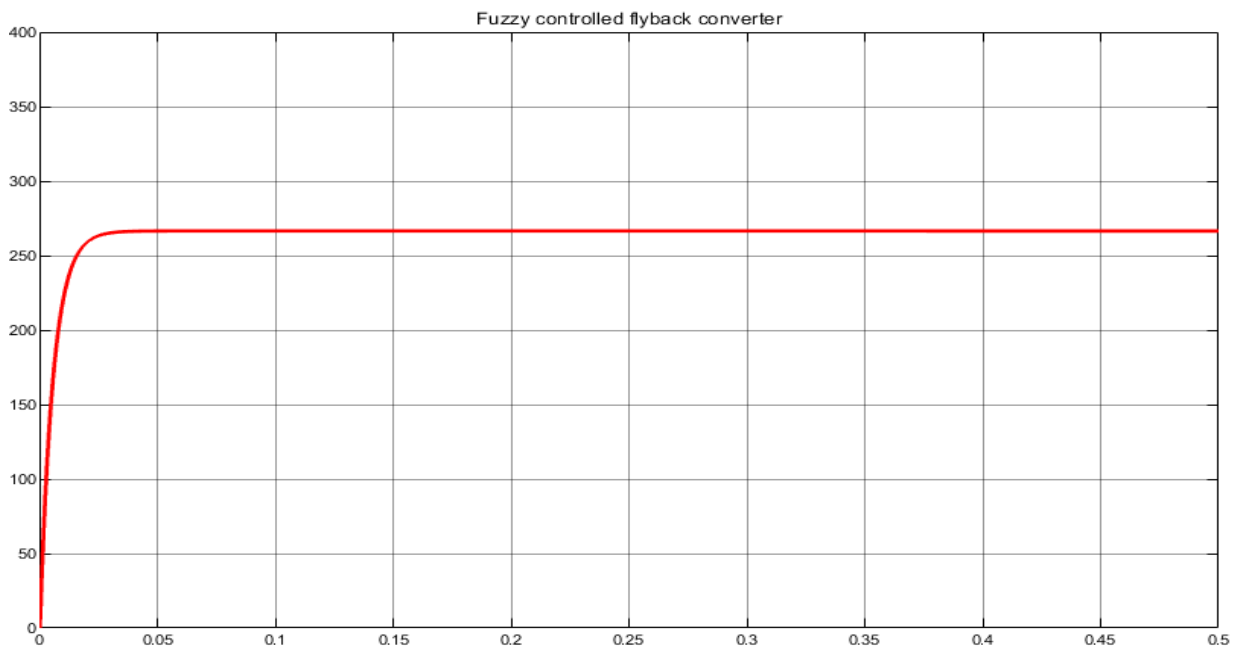

Fig.7.Output voltage for Fuzzy controlled fly back converter

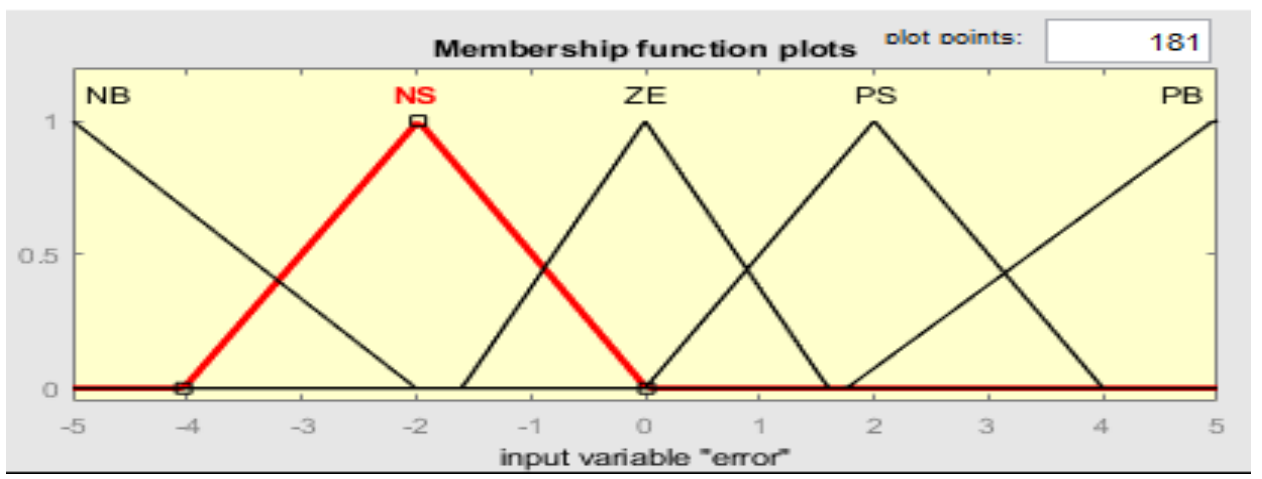

Fig.8. Membership function plot for error

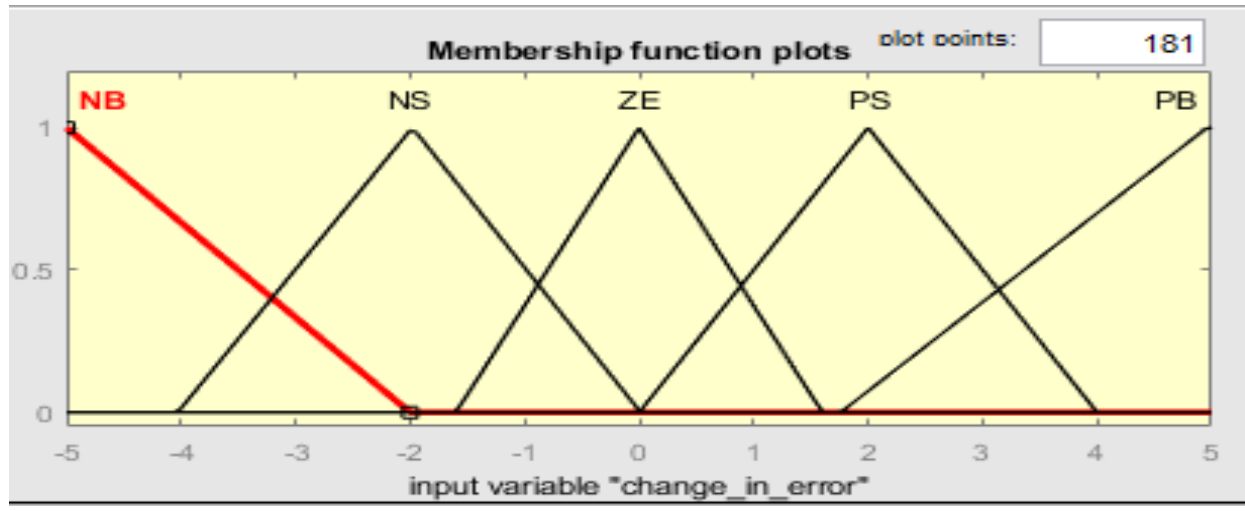

Fig. 9. Membership function plot for change in error 


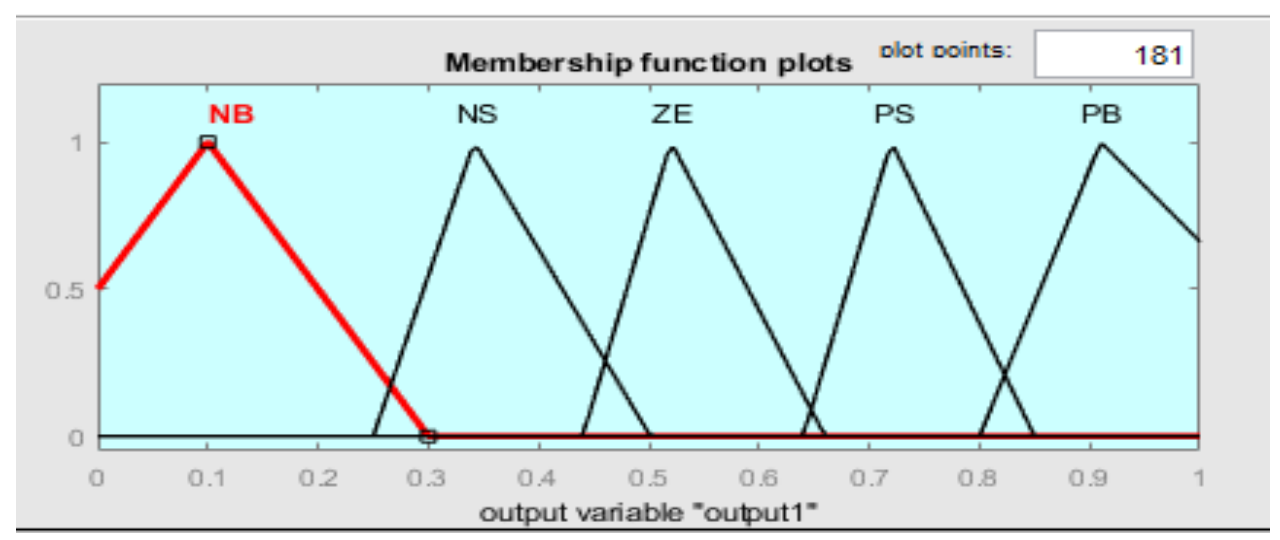

Fig. 10. Membership function plot for output

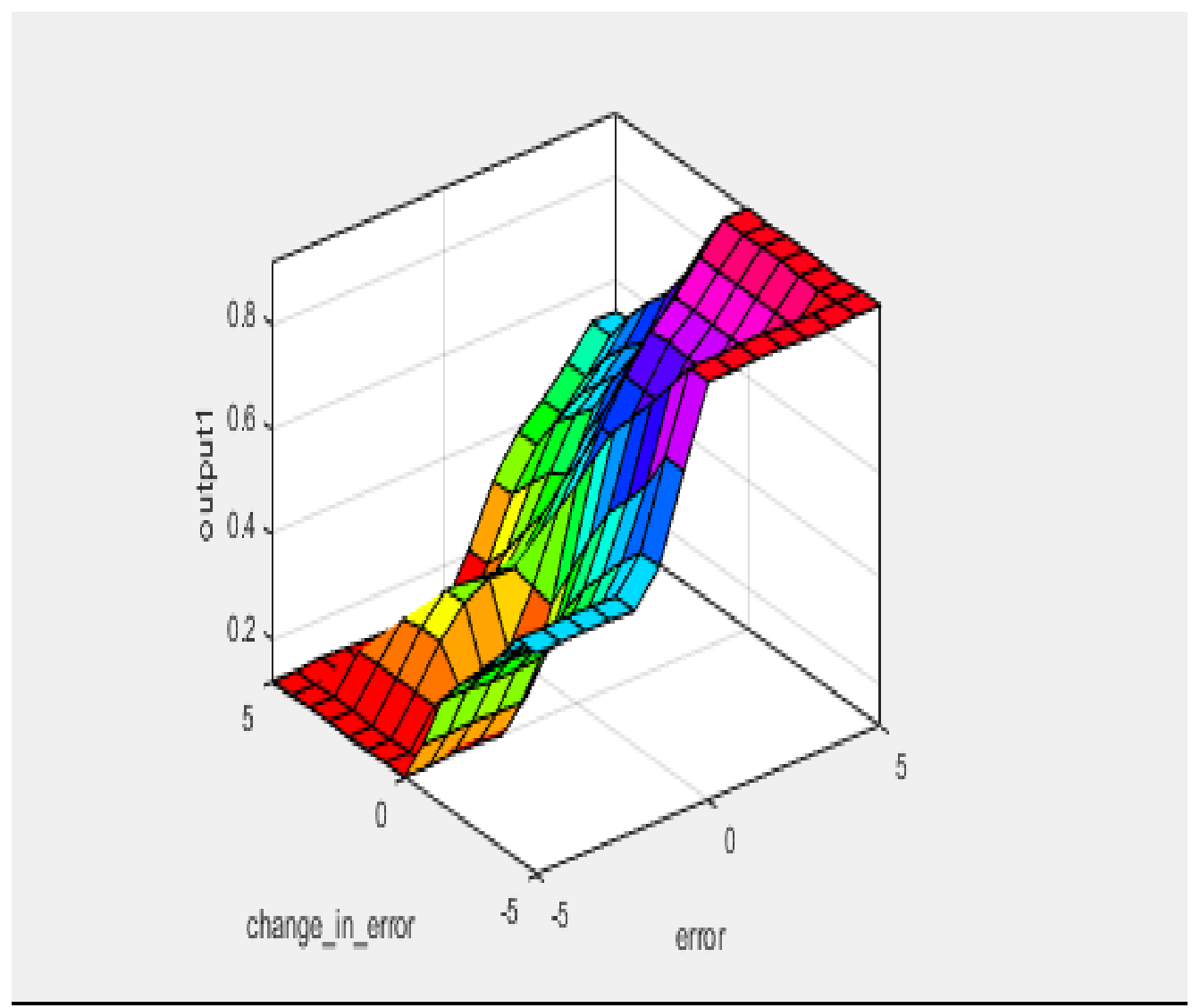

Fig. 11. Surface view plot for error and change in error 


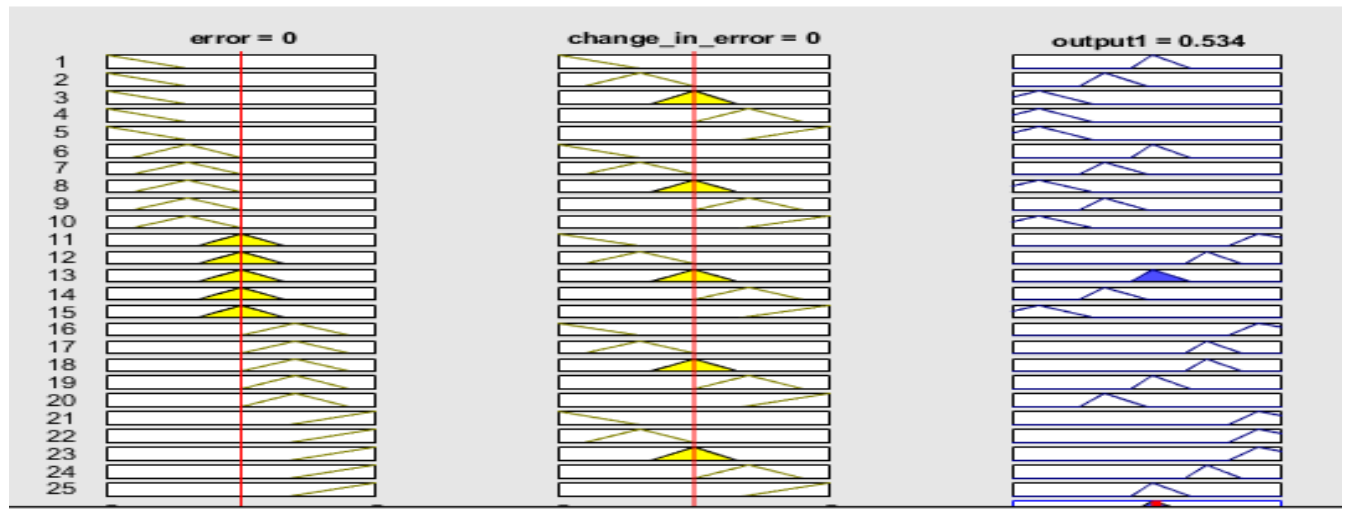

Fig. 12. Rule viewer plot for error, change in error and output

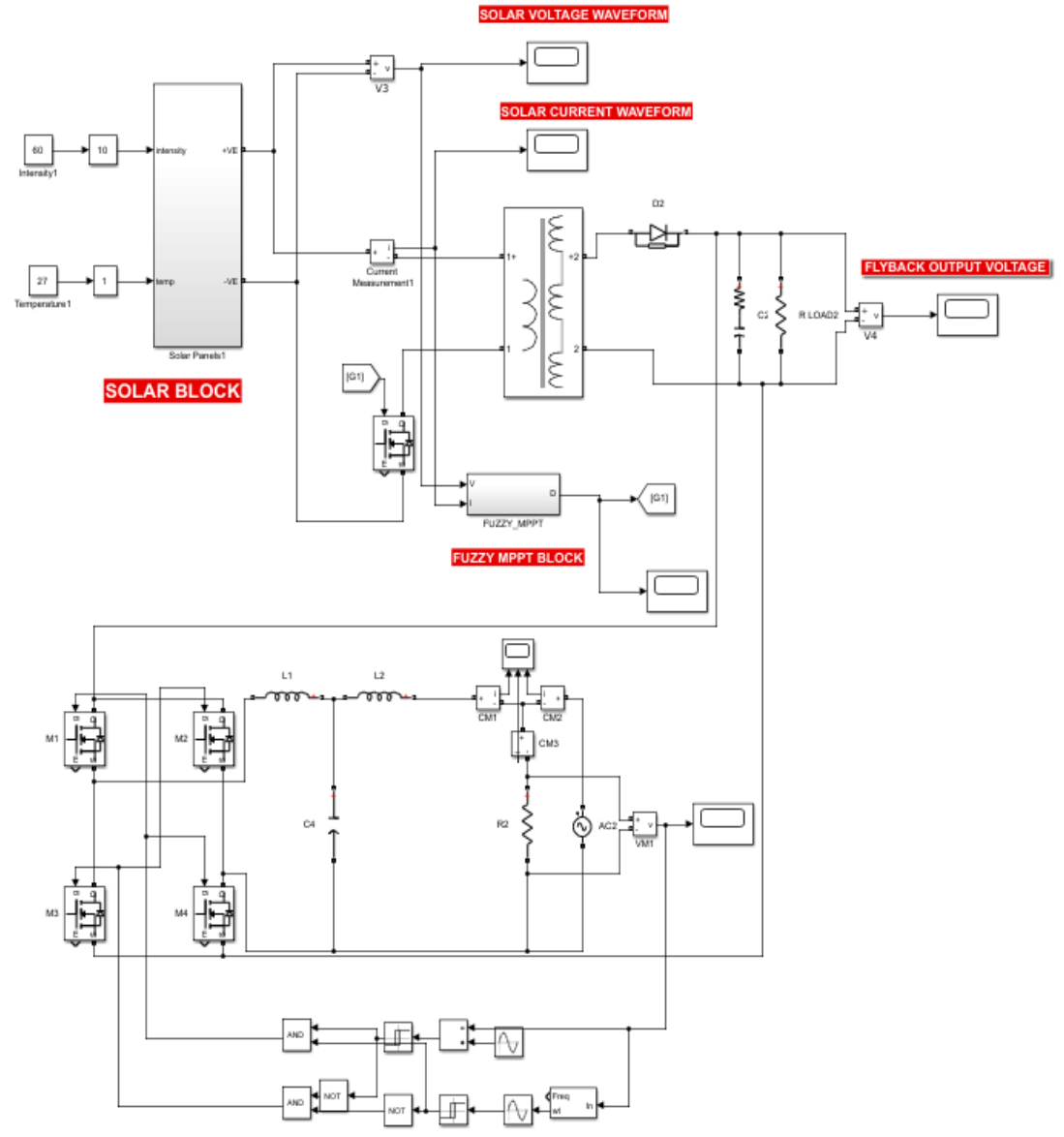

Fig. 13. Closed loop simulation circuit using SMC and Fuzzy logic controller 


\section{Sliding Mode controller technique for H- Bridge Inverter}

In sliding mode controller (SMC), a sliding surface acts as the reference path for state variable that has to be controlled to attain the desired equilibrium. The state variables may be error or deviation of error. Non linear controller SMC controls variable structure systems. Some of the advantages which makes it suitable are its stability, robustness, easy implementation. The output from Fly back converter is fed to the inverter circuit controlled by SMC. The simulation diagram is show in figure 13. The output obtained form inverter using $\mathrm{SMC}$ and its harmonic analysis is shown in figure 14 and 15 respectively.

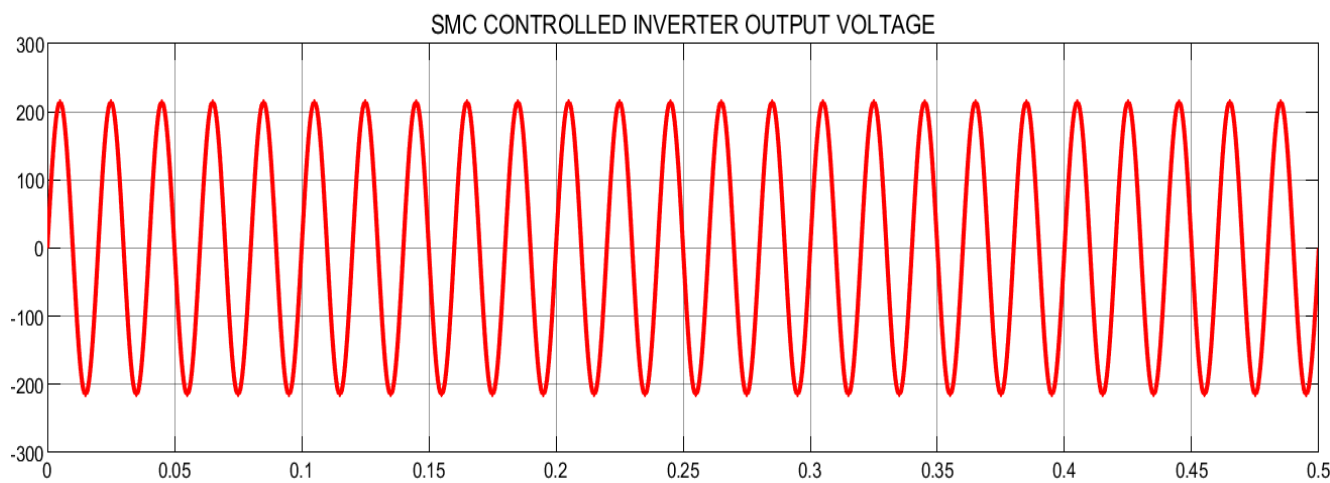

Fig. 14. Inverter output voltage

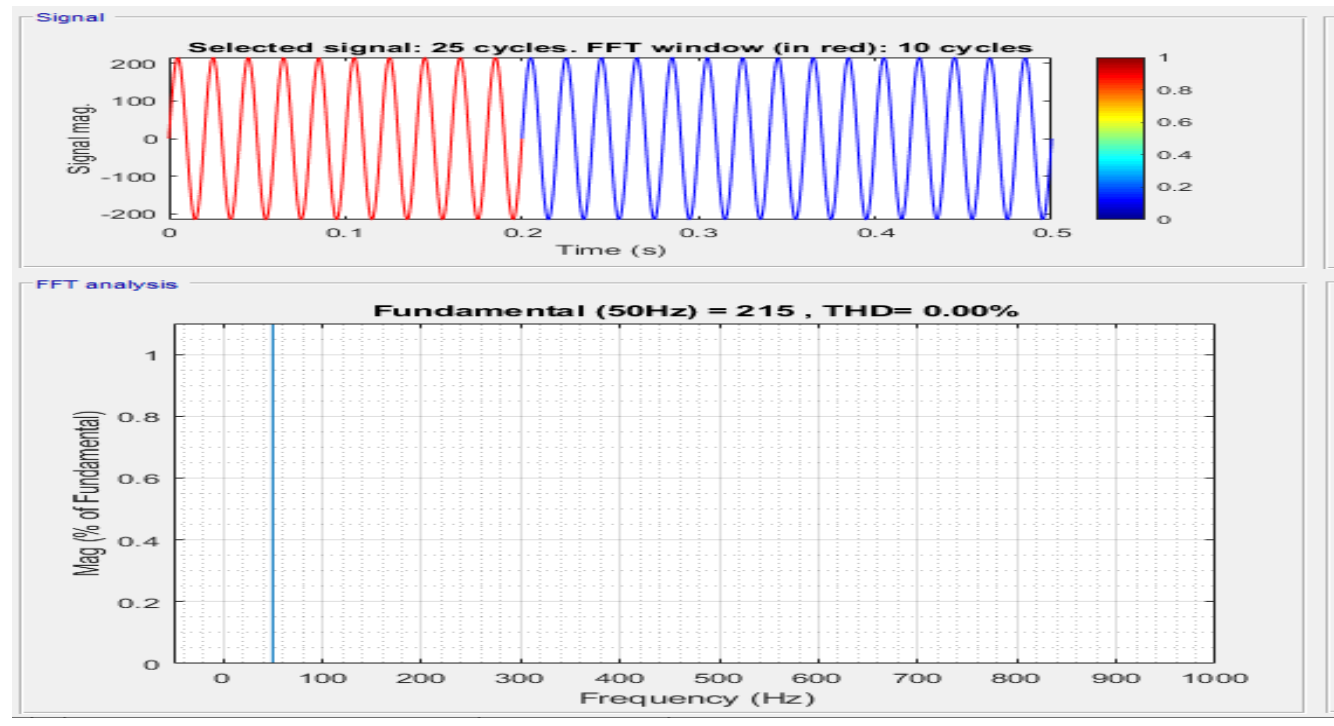

Fig. 15. THD for Inverter output Voltage 


\section{Hardware Results}

The hardware model consists of a two-way source with one way is $12 \mathrm{v} 1 \mathrm{~A}$ solar panel and the other will be by $220 / 12 \mathrm{~V}$ DC supply. The voltage obtained is $14.38 \mathrm{~V}$ which is fed to the fly back converter which boosts the voltage to $132.7 \mathrm{~V}$. The fuzzy logic MPPT decides the duty cycle value for the converter. For this, the current and voltage values are measured by the current and the voltage transformers respectively and are fed to the controller in the prototype model. The controller consists of a PIC microcontroller in which the code is done in a kit and then it is embedded in the PIC Microcontroller. The controller feeds the duty cycle to the fly back converter and the LC filter is used to remove the harmonics from the voltage. The diode is used for taking only the DC component of the boosted voltage. The boosted output voltage from fly back converter is fed to the H-bridge inverter in which a load is connected in parallel. RMS AC output voltage obtained is $83.1 \mathrm{~V}$. The voltage has been filtered by the LC filters before feeding it to the load. The load consists of a zero-wattage bulb which typically needs $12 \mathrm{~W}$ consumable power. The bulb glows at its full power at constant brightness level over time. The figure 16 shows the prototype implemented with solar panel. The voltage is boosted nearly 6 times that of input with a stable voltage supply for the load. The figure 17 prototype developed for inverter output voltage of value $82 \mathrm{~V}$ for PV input of $12 \mathrm{~V}$. In hardware open loop inverter circuit gives $82.1 \mathrm{~V}$. SMC implemented hardware will yield more efficiency when compared to that of open loop.

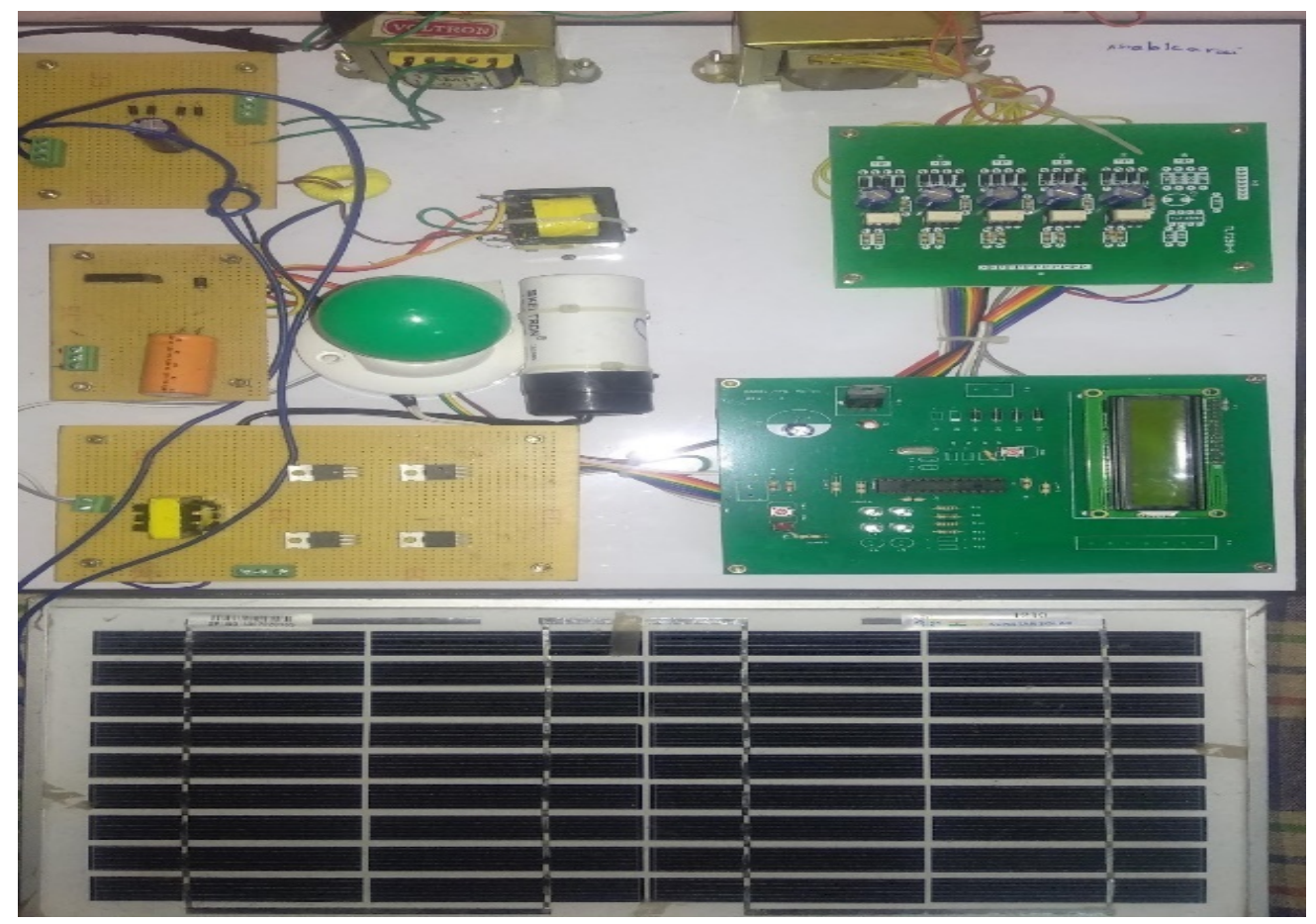

Fig. 16. Hardware model using PV panel 


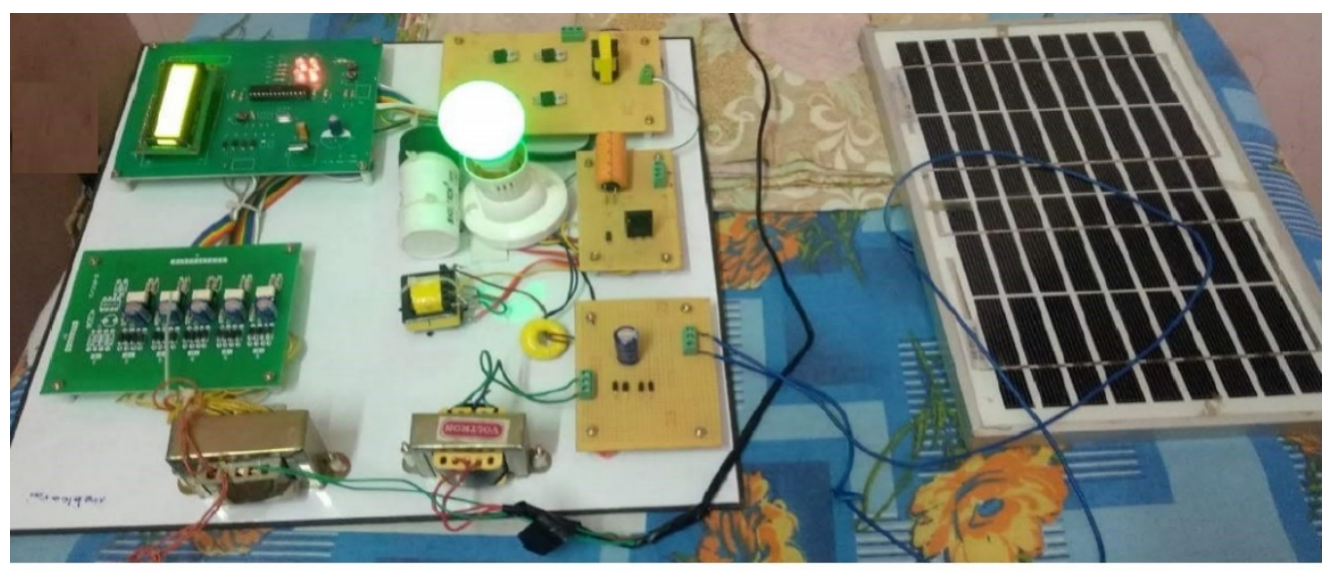

Fig. 16. Inverter output voltage measured

\section{Conclusion}

The fly back converter has proved to be an effective way of achieving a boosting voltage. The inverter has obtained a stable voltage output throughout the operation period at a minimal loss of voltage due to harmonics. The experimental observations show that the output converter voltage has been boosted to nearly 6 times that of the input voltage fed by PV. Thus, simulation model is most promising model for verifying that the model is practically reliable. Moreover, the hardware model shows that the proposed approach of boosting the voltage can be implemented on a large-scale basis to fulfill the requirement of high voltage application. This also gives us a promising hope to utilize solar power in the best way by maximizing the efficiency of power conversion. Thus, a cost-effective solution for maximizing the output achieved using fly back converter, fuzzy logic and SMC controller.

\section{References}

[1] G.M.L. Chu, D.D.C. Lu, V.G. Agelidis: "Flyback-based high step-up converter with reduced power processing stages", IET Power Electron., Vol. 5, Iss. 3, 2012, pp. 349-357.

[2] B. Bendib, F. Krim, H. Belmili, M. F. Almi, S. Boulouma: "Advanced Fuzzy MPPT Controller for a stand-alone PV system, B. Bendib et al. / Energy Procedia 50, 2014, pp. 383 - 392.

[3] Zhangyong Chen, Qun Zhou, Jianping Xu: "Coupled-inductor boost integrated flyback converter with high-voltage gain and ripple-free input current”, IET Power Electron., Vol. 8, Iss. 2, 2015, pp. 213-220.

[4] Heng-Yi Li, Lon-Kou Chang: "A Single-Stage Single Switch Parallel AC/DC Converter Based on Two Output Boost-Flyback Converter", 37th IEEE Power Electronics Specialists Conference, 2006, pp. 1-7. 
[5] Mahrous El-Sayed Ahmed, Mohamed Orabi, Omar Mohamed AbdelRahim, "Two-stage micro-grid inverter with high-voltage gain for photovoltaic applications", IET Power Electron., Vol. 6, Iss. 9, 2013, pp. 1812-1821.

[6] Sivagami, P., Jothiswaroopan, N.M., "Optimal Control Strategy Using PV Based LUO Converter for a Micro Grid to an Unelectrified Zone", Journal of Green Engineering, Vol. 10_2, 463479.Alpha Publishers.

[7] Pushpavalli, M., Jothi Swaroopan, N.M, "Maximum Power Tracking for PV Array System Using Fuzzy Logic Controller" Advances in Intelligent Systems and Computing,2019, 846, pp. 337-348.

[8] P Illavarason, Renjith J Arokia, P Mohan Kumar, 2019, "Comparative study and an improved algorithm for iris and eye corner detection in real time application "Computer-Aided Developments: Electronics and Communication, CRC Press, PP-91-98. 